\title{
Nutritional ecology of the wild rabbit-an input to the timing of reproduction
}

\section{By I. L. BoyD* and C. J. Bray, Institute of Terrestrial Ecology, Monks Wood, Abbots Ripton, Huntingdon PE17 2LS}

The rabbit (Oryctolagus cuniculus) has become adapted to a wide range of environmental conditions, from arid desert to wet temperate. Each environmental type imposes a different set of constraints on reproduction and growth. In arid Australia, reproduction is synchronized with the rains (Wood, 1980), which occur in an unpredictable pattern, whereas in the predictable seasonal environment of northern Europe, reproduction begins in advance of increased pasture growth in spring (Boyd, $1986 a, b$; Boyd \& Myhill, 1987). The present paper concerns the processes by which rabbits in the wild synchronize their input to reproduction and growth with seasonal cycles in their environment.

Nutrition is the most important single environmental factor impinging on reproduction and growth. The strategy for reproduction and growth will be aimed at minimizing energy deficits and utilizing energy surpluses, assuming specific nutrients are not limiting. Thus, in Britain most births occur between March and August when there is maximal pasture growth, and there are few births during the autumn and winter (Boyd \& Myhill, 1987). However, synchronization with environmental conditions can be imposed in two ways. First, offspring of animals that reproduce during periods of food shortage will have low survival and low reproductive success and, second, physiological processes may have evolved to reduce the probability of births occurring at times when food is short. Daylength may be used to synchronize reproductive cycles with nutritional conditions (Sadleir, 1969; Lincoln \& Short, 1980) because, as a seasonal oscillator, it can predict the onset of suitable conditions for reproduction. This may be important in the majority of mammals where maturation of the testes, after a period of regression, can take 1-2 months (Setchell, 1978).

Daylength is a potent factor controlling reproductive seasons in a wide range of mammals, including rabbits (Boyd, 1986b, 1987) but some studies have also shown that nutrition can directly synchronize seasonal cycles (Nelson et al. 1983; Irby et al. 1984). In the starling, nutrition apparently has no role in the proximate control of the timing of reproduction, which is entirely controlled by daylength (Dawson \& Goldsmith, 1984) and, therefore, selection pressure will focus the reproductive season on the time of year when food is most abundant. Hence, inputs from the environment to control the timing of the reproductive effort in rabbits may be mainly photoperiodic, but because of the apparent adaptability of rabbit breeding cycles to local conditions, we would also expect to find that other environmental variables such as nutrition could affect the reproductive season.

The present paper describes experiments on male wild rabbits. Males have been used because measurements of testicular size are a convenient non-invasive method of assessing reproductive condition.

\section{Timing of reproduction}

When rabbits were kept on natural pasture in an enclosure under semi-natural conditions, males ( $n$ 7) showed a cycle of testicular regression and regrowth (Fig. 1) which lasted 1 year, and which was similar to the cycle observed in the wild (Boyd \& Myhill, 1987). Testicular size, which correlated with the presence of spermatogenesis

*Present address: British Antarctic Survey, Madingley Road, Cambridge CB3 0ET. 


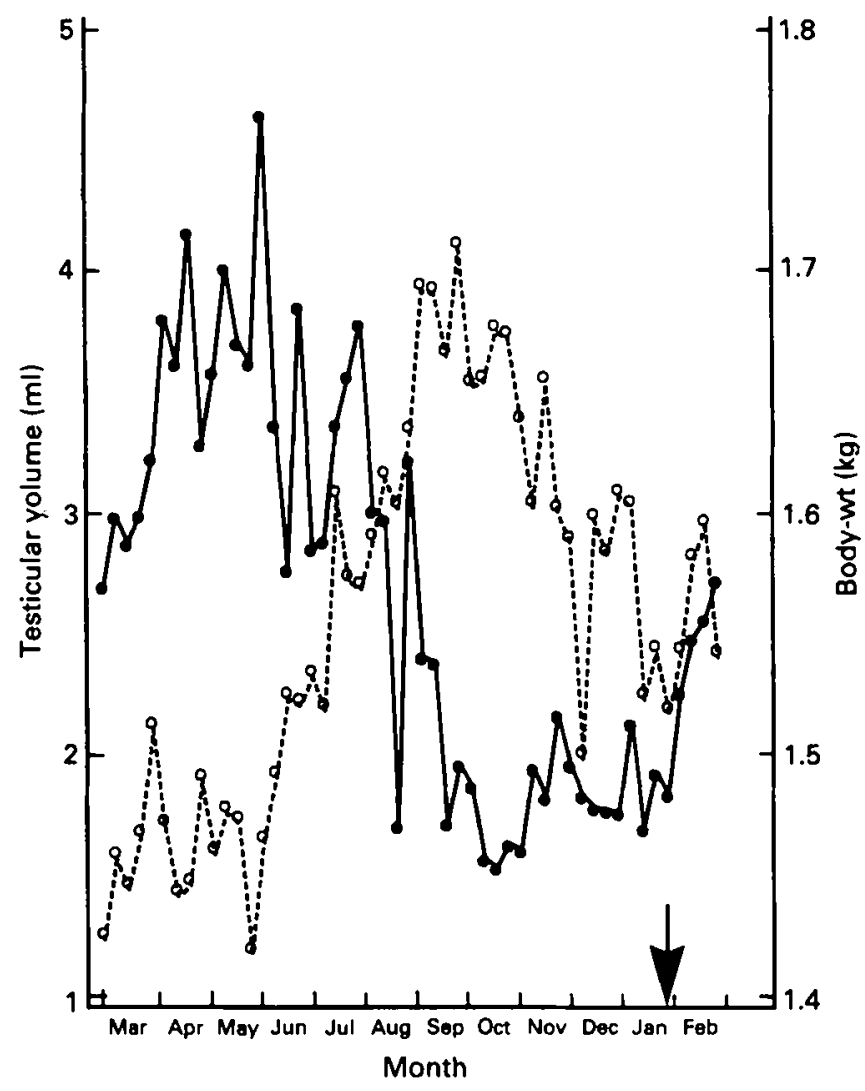

Fig. 1. Changes in the mean testicular volume (- $)$ and mean body-weight $\left(0-0_{-}\right)$of seven adult male wild-type rabbits kept in a 0.8 ha enclosure and fed on natural pasture over 1 year. Results are expressed as weekly means. Females were present in the enclosure with these males. $\downarrow$, The point at which supplementary feeding began.

(Boyd, 1985), was maximal in the spring and summer and minimal in the autumn and winter. This cycle was clearly correlated with changes in the food supply through the year, because most food will be available during the spring and summer. There were some signs that the testicular cycle may have a degree of dependence on food availability, because testicular regrowth only occurred after supplementary food was given (Fig. 1).

There was also a significant negative correlation between testicular volume and body-weight $(P<0.001)$, because there was a strong cycle of body-weight which was out of phase with the cycle of testicular size (Fig. 1). This meant that body-weight increased as testicular size declined and that body-weight was maximal in the autumn. These weight changes are correlated with changes in fat reserves, which may be partly a consequence of changes in circulating levels of sex hormones (Dark et al. 1983). Boyd \& Myhill (1987) showed that an index of kidney fat was correlated with body-weight, and with body-weight minus the gut weight, but fat content constitutes only a small proportion of body-weight (Table 1), suggesting that much of the annual cycle of weight change is caused by a change in muscle mass. 


\section{Table 1. Analysis of body composition of wild-type rabbits}

(Rabbits were dissected to remove all subcutaneous and inguinal fat (dissectable fat). Each carcass was dried in a vacuum oven at $60^{\circ}$ to constant weight to provide a measure of water content. Fat was extracted from the remainder by reflux distillation in dichloromethane and weight loss provided a measure of total fat weight. Values are means and standard deviations for ten animals)

\begin{tabular}{lrr} 
& \multicolumn{1}{c}{ Mean } & \multicolumn{1}{c}{ SD } \\
Body-wt $(\mathrm{g})$ & 1412.68 & 166.89 \\
Water wt $(\mathrm{g})$ & 967.43 & 101.89 \\
Total fat wt $(\mathrm{g})$ & 51.06 & 34.54 \\
Dissectable fat wt $(\mathrm{g})$ & 21.26 & 15.88
\end{tabular}

These results suggest that the annual cycle has two phases, during one of which resources are channelled into reproduction, and during the other are channelled into growth of body reserves.

\section{Effect of photoperiod under constant nutrition}

Wild-caught rabbits were maintained in the laboratory to find what effect daylength has in controlling the annual cycle. Nutrition was held constant in this case. The method involved the capture of adult rabbits from the wild during the winter when testicular size is either small or increasing. Rabbits were then held individually in cages and kept in summer daylengths of $16 \mathrm{~h}$ of light/d (16L-8D) for a minimum of 10 weeks. Some rabbits $(n 5)$ were then returned to winter daylengths of $8 \mathrm{~h}$ of light/d $(8 \mathrm{~L}-16 \mathrm{D})$, while controls ( $n$ 5) were kept in summer daylengths. Another group was kept in summer daylengths and given subcutaneous implants (Boyd, 1985) of the pineal hormone melatonin, which has the effect of simulating exposure to short daylengths (Reiter, 1980; Boyd, 1985). All rabbits were given a standard diet of rabbit pellets ad lib. throughout, and water was also freely available. Temperature was not closely controlled but varied within the same limits for each group.

The decline in daylength at the change between $16 \mathrm{~L}-8 \mathrm{D}$ and $8 \mathrm{~L}-16 \mathrm{D}$ was designed to model the decline in daylength following the summer solstice when reproductive regression normally occurs. This treatment caused a degree of testicular regression compared with controls, and 3 weeks after the transfer the group in winter daylengths had significantly smaller testes than the controls $(P<0 \cdot 01)$ (Fig. $2(a$ and $b)$ ). However, 11 weeks after the transfer to short daylengths the testes began to regrow, and this continued until the testes recovered to full size. This regrowth occurred at the same time of year as these rabbits would have been expected to experience testicular regression had they been in the wild. While there was a gradual decline in the testicular size of the controls, they did not show the pattern of regression followed by regrowth seen in the group treated with winter daylengths after week 11 . However, they did experience testicular regression when transferred to winter daylengths after week 35 . Rabbits implanted with melatonin showed a pattern of testicular regression and regrowth similar to that of rabbits treated with winter daylengths and different from the controls (week $14, P<0.05$ ). This shows that, under constant nutritional conditions, daylength can affect testicular growth cycles. It also suggests a mechanism for the control of the annual cycle in rabbits; declining daylength in late summer may induce testicular regression and, after a period of 10-12 weeks, regrowth of the testes then occurs spontaneously. As shown by Boyd (1986a), re-exposure to summer daylengths then resensitizes rabbits to a subsequent decline in daylength. 

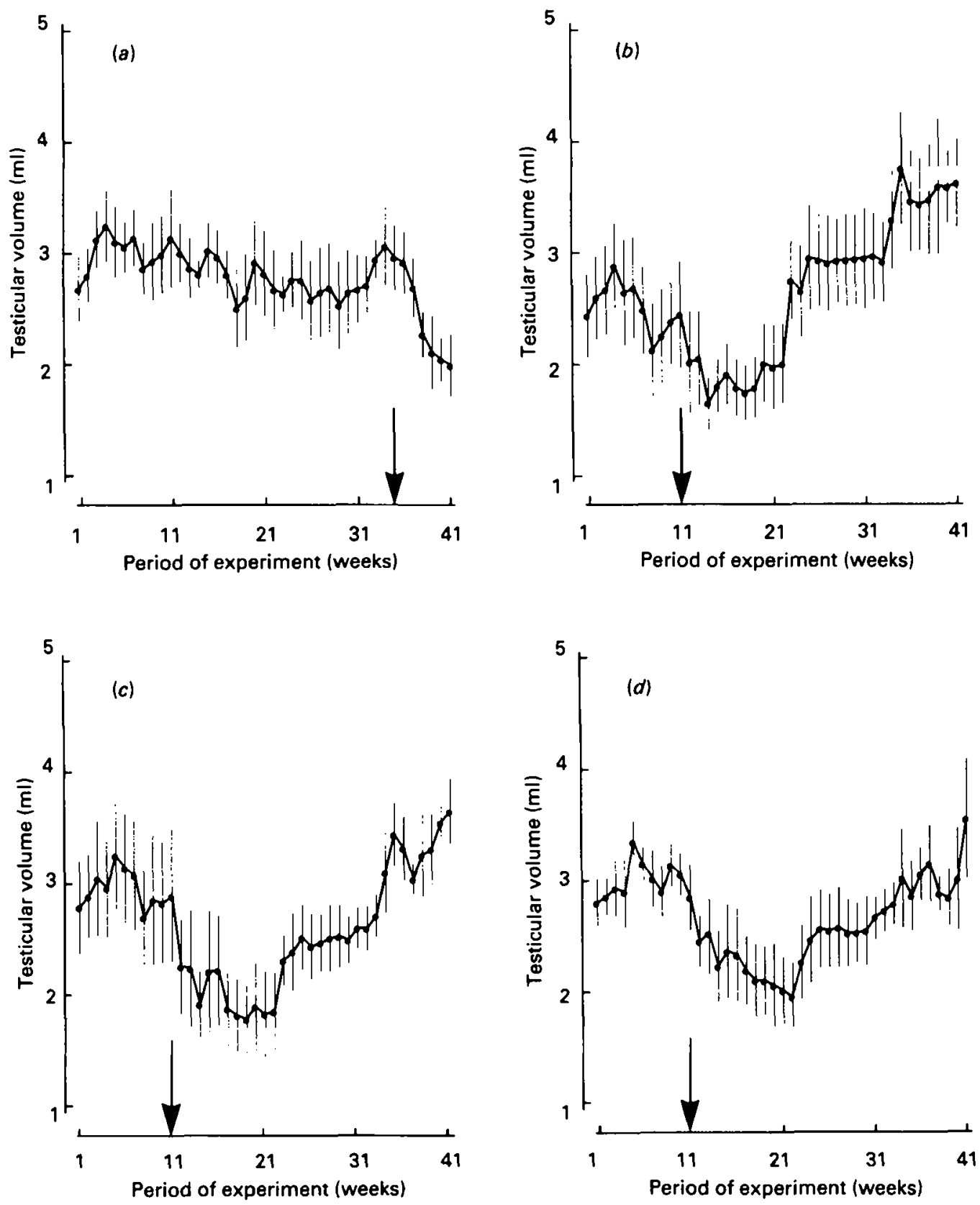

Fig. 2. The effect of changes in photoperiod on testicular volume of four groups ( $n 5$ for each group) of adult rabbits caught from the wild between November and January. Testicular volume was measured weekly and expressed as a mean for each group. (a) Group 1 was kept in summer daylengths $(16 \mathrm{~L}-8 \mathrm{D})$ for 34 weeks then transferred to winter daylengths $(8 \mathrm{~L}-16 \mathrm{D})$ in week 35 . (b) Group 2 was transferred to winter daylengths $(8 \mathrm{~L}-16 \mathrm{D})$ after 10 weeks in $16 \mathrm{~L}-8 \mathrm{D}$. (c) Group 3 was given subcutaneous implants containing melatonin in week 11 and was kept in $16 \mathrm{~L}-8 \mathrm{D}$ throughout. $(d)$ Group 4 was given identical implants containing 6-methoxybenzoxazolinone in week 11 and was kept in 16L-8D throughout. $\downarrow$, Times when daylength was changed or when implants were given. Values are means with one standard error represented by vertical bars. 


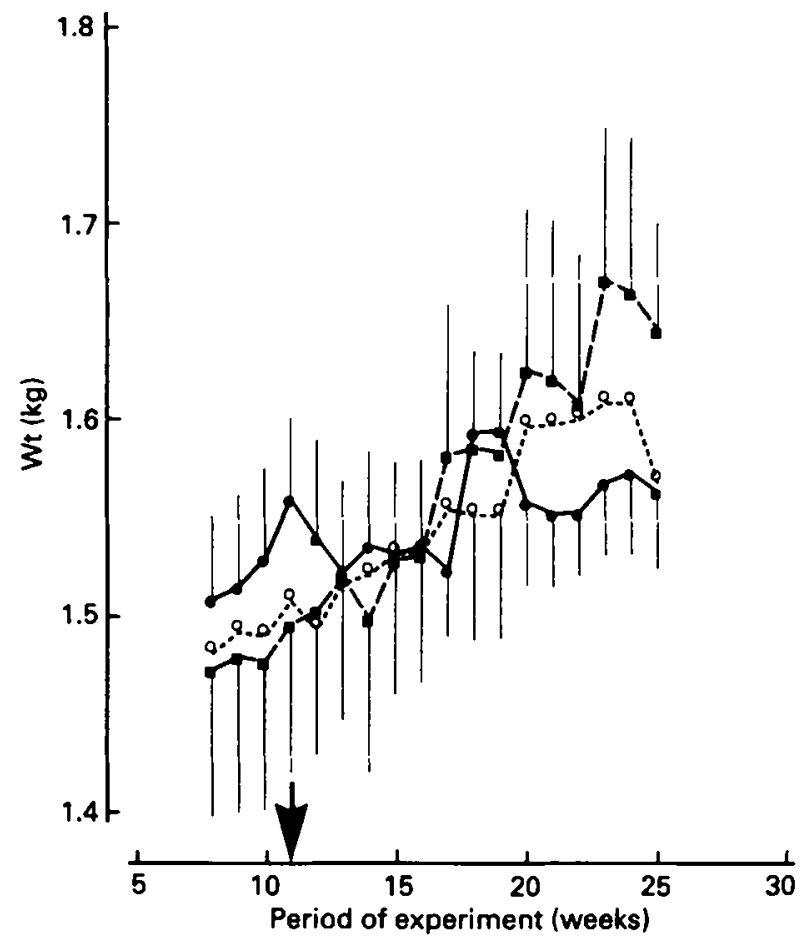

Fig. 3. The weight changes occurring in groups $1(-0), 2\left(a_{-} \ldots\right)$ and $3(0 \ldots-0)$ during the experiments. Group 1 was kept in summer daylengths $(16 \mathrm{~L}-8 \mathrm{D})$ for 34 weeks then transferred to winter daylengths $(8 \mathrm{~L}-16 \mathrm{D})$ in week 35 , group 2 was transferred to winter daylengths $(8 \mathrm{~L}-16 \mathrm{D})$ after 10 weeks in $16 \mathrm{~L}-8 \mathrm{D}$, group 3 was given subcutaneous implants containing melatonin in week 11 and was kept in $16 \mathrm{~L}-8 \mathrm{D}$ throughout. Results are expressed as weekly means with one standard error represented by vertical bars. $\downarrow$, Time when daylength was changed or when melatonin implants were given.

Measurements of body-weight made during part of this study (Fig. 3) showed no trend to suggest that the increase observed in the rabbits kept on natural pasture (Fig. 1) was caused by changes in daylength. However, the rabbits kept in cages, although reproductively active in terms of the presence of spermatogenesis, were not active in the true sense, and, therefore, did not incur the normal energy costs of reproduction in the wild. Thus, rabbits in the laboratory may not show concomitant changes in body-weight. They did, however, show significant differences in their rates of food intake. Food intake was measured continuously by weight difference of the food hopper of each rabbit when filled on successive occasions. Spillage of food was negligible. This showed that food intake in rabbits from the control group declined, whereas the intake of rabbits transferred to winter daylengths remained elevated and significantly greater $(P<0.001)$, in most weeks, than the intake of the controls (Fig. 4). The food intake of rabbits in the group implanted with melatonin was mid-way between, but significantly greater $(P<0.05)$ than that of rabbits in summer daylengths and of rabbits in winter daylengths.

This suggests that rabbits in winter daylengths eat more than rabbits in summer daylengths, and that the process of daylength measurement involving melatonin has at least a partial role to play in this. The difference between the food intake of rabbits given melatonin and those given winter daylengths may be accounted for by the fact that rabbits are generally nocturnal in habit, and giving them $16 \mathrm{~h}$ of darkness/d compared with $8 \mathrm{~h}$ may mean they have more hours in which to eat. However, the fact that the body-weights of rabbits in the three groups were not significantly different $(P>0.05)$ at 


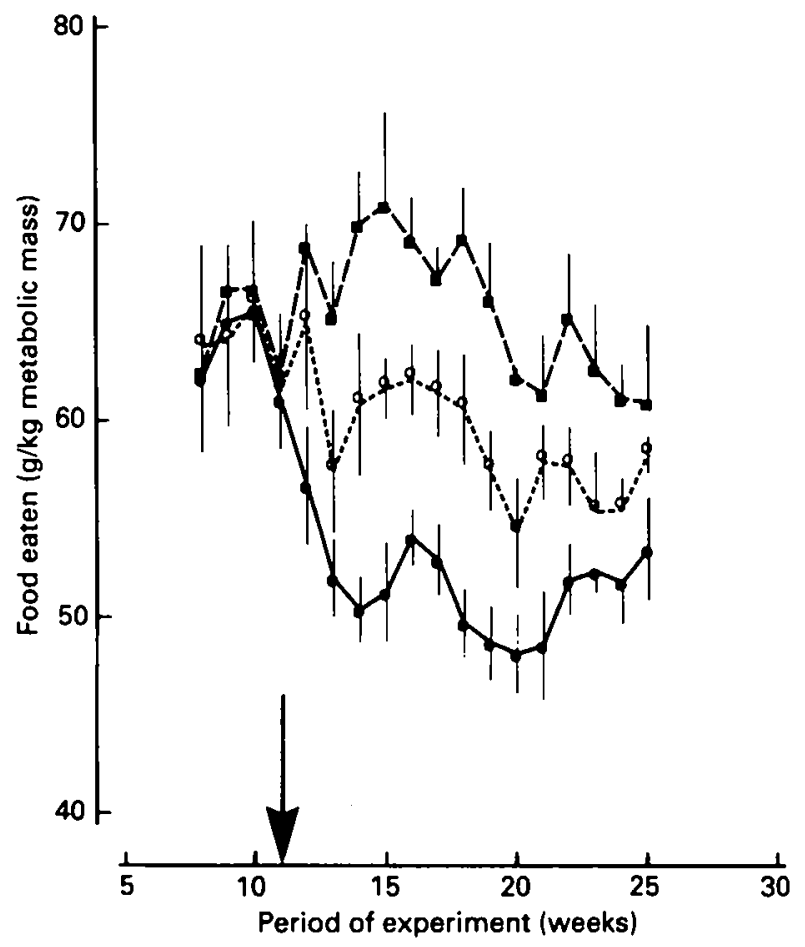

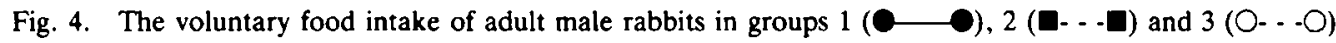
during the experiment. Group 1 was kept in summer daylengths (16L-8D) for 34 weeks then transferred to winter daylengths $(8 \mathrm{~L}-16 \mathrm{D})$ in week 35 , group 2 was transferred to winter daylengths $(8 \mathrm{~L}-16 \mathrm{D})$ after 10 weeks in 16L-8D, group 3 was given subcutaneous implants containing melatonin in week 11 and was kept in 16L-8D throughout. Results are expressed as weekly means with their standard errors represented by vertical bars. $\downarrow$, Time when daylength was changed or when melatonin implants were given.

any stage of the experiment (Fig. 3) suggests that the difference in food intake of up to $30 \%$ was not translated into changes in body reserves.

\section{Effect of changing plane of nutrition}

The results shown in Fig. 1 suggested that regrowth of the testes of rabbits may have been dependent on nutrition, because regrowth only occurred after additional food had been given. However, the results of the manipulation of daylength in the laboratory showed that, after the start of regression, there was a period of 10-12 weeks before the start of testicular regrowth. Other studies have also suggested a period of similar length for rabbits (Boyd, 1985, 1986a). Hence, rabbits would be expected to have redeveloped testes by December, and this was not the case for the rabbits illustrated in Fig. 1. The obvious hypothesis was that, since body-weight was in decline at that time, these rabbits were experiencing some nutritional stress which prevented testicular regrowth. This was tested in the laboratory with rabbits kept in conditions similar to those described for the previous experiment. There were two groups of rabbits and both were subjected to the same photoperiodic regimen. Adult rabbits were caught from the wild during September and October when the testis size was minimal. These were then kept in simulated natural daylengths for $52^{\circ} \mathrm{N}$ until week 12 of the experiment when they were transferred to summer daylengths (16L-8D). Rabbits in the control group were fed ad lib. with rabbit pellets, while those in the other group were given a weighed amount of food (gross 

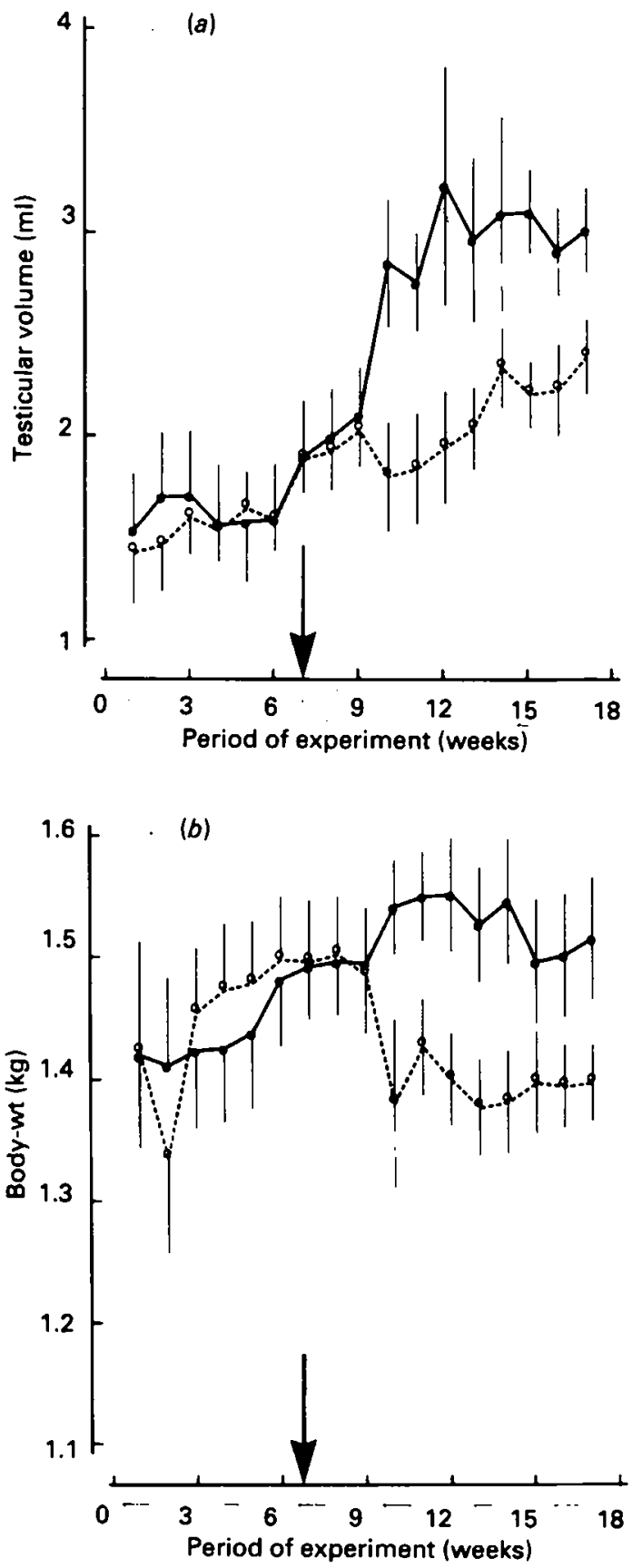

Fig. 5. The change in testicular volume $(a)$ and body-weight $(b)$ of adult male rabbits taken from the wild during September and October and fed ad lib. throughout (-) or fed ad lib. until week 7 when a diet of $70-80 \%$ of the ad lib. voluntary food intake was given $\left(\mathrm{O}_{-}-\mathrm{O}\right)$. Both groups were kept in identical daylengths. Results are expressed as weekly means with their standard errors represented by vertical bars. $\downarrow$, Diet of $O-O$ group changed. 
energy $18.2 \mathrm{MJ} / \mathrm{kg}$ body-weight) each day. This amounted to 1050 (SE 7.73) kJ/d, which was designed to fall between 70 and $80 \%$ of the energy intake of rabbits in the control group. The net effect of this treatment was to reduce the growth of the testes in rabbits on a low plane of nutrition, although it did not prevent growth (Fig. 5). It is also worth noting that, despite the reduced plane of nutrition, the body-weights of these rabbits eventually stabilized, suggesting that they had been able to adapt to the negative energy balance induced by the introduction of the lower plane of nutrition.

During the period of food restriction all rabbits were given a constant weight of food each day, meaning that large rabbits, which have a greater energy requirement than small rabbits, would have experienced a relatively higher degree of energy restriction. There was a significant negative correlation $(P<0.005)$ between the maximum bodyweight of each rabbit, measured during the pretreatment period, and the change in testicular weight during the period of dietary restriction. This shows that the testicular growth of larger individuals, which experienced a lower energy intake per unit body-weight than smaller individuals, was most affected by the restriction of the diet.

A similar experiment was carried out on rabbits which had fully developed testes and were in summer daylengths, where one group was given ad lib. food and a second group was given $70-80 \%$ of the intake of the ad lib. group. This treatment caused the testes to decline to a significantly smaller size than controls $(P<0 \cdot 01)$ (Fig. 6), although body-weight also declined throughout this experiment, suggesting that these rabbits had a negative energy balance while on the lower plane of nutrition. Hence, the plane of nutrition can affect the reproductive changes occurring in the annual cycle.

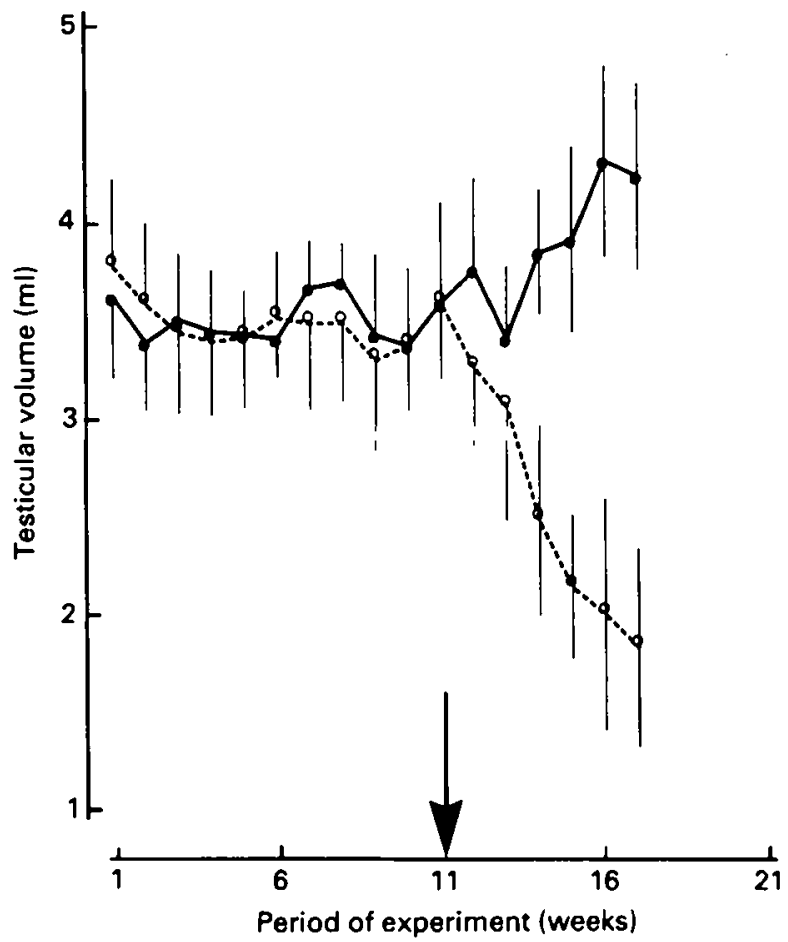

Fig. 6. The change in the testicular volume of reproductively-active adult male rabbits in summer daylengths resulting from a reduced diet of $70-80 \%$ of the ad lib. intake $(0--0)$ given from week $11(\downarrow)$ or in rabbits on an ad lib. diet ( $\longrightarrow$ ). Results are weekly means with their standard errors represented by vertical bars. 


\section{The effect of diet quality}

Some studies have detailed how quality of diet affects the reproductive output of female domestic rabbits (Partridge \& Allan, 1982; Adams, 1983; Partridge et al. 1986), but none has considered its implications for wild rabbits exposed to seasonal cycles of pasture condition. Photoperiod provides a generalized cue to synchronize reproduction with the time of year when pasture condition would normally be expected to be improving, or be at its peak. Negus \& Berger (1977) suggested that herbivores utilize specific compounds in the diet which have no innate nutrient value, but which herald the onset of changing nutritional conditions. Experimental studies have confirmed both the presence of such a compound, 6-methoxybenzoxazolinone (6MBOA), in growing plant tissue (Epstein et al. 1986), and its potency in terms of its effects on mammalian reproduction (Berger et al. 1981; Butterstein et al. 1985). In common with Yuwiler \& Winters (1985), we observed a structural similarity between 6MBOA and the endogenous hormone melatonin, and we hypothesized that it may act as a natural analogue of melatonin, and its presence in the diet may modify the animal's response to melatonin (Fig. 2(c)).

To test this, we included a fourth group in the experiment already described in Fig. 2. This group was given subcutaneous implants of $6 \mathrm{MBOA}$, similar to the melatonin implants (Fig. $2(c$ and $d)$ ). This showed that 6MBOA caused the same pattern of testicular regression, followed by regrowth, as occurred when rabbits were exposed to short daylengths or melatonin (Fig. 2). Hence, 6MBOA has properties analogous to those of melatonin. Yuwiler \& Winters (1985) showed that 6MBOA may have a site of action in the pineal gland, and that it may stimulate melatonin biosynthesis. There is a similarity between the dose-response effect of melatonin on the gonadal size of golden hamsters (Turek et al. 1975), and the same relationship for 6MBOA in the montane vole (Sanders et al. 1981). While most studies suggest melatonin and 6MBOA have contrasting effects on gonadal function, this may be a consequence of different dosing procedures, which can themselves affect the efficacy of melatonin treatment (Reiter, 1980; Reiter et al. 1981; Vaughan et al. 1986).

\section{Conclusions}

The profound seasonal changes in the reproduction of wild rabbits are probably controlled by a range of environmental factors, including nutrition and photoperiod. While photoperiod may have a general permissive role in determining when reproduction occurs, it cannot provide an accurate indication of changing local environmental conditions. This is particularly relevant to rabbits that live in highly-localized social groups where the food supply will vary according to local management, physiography and intra-specific competition. Rabbits, generally, have low levels of energy reserves, and probably have short-term energy budgets, which means they will be sensitive to changes in local conditions. Hence, we should expect the physiology of these animals to be closely integrated with changes in their food supply. We should also expect mechanisms to have evolved which will predict the onset of changes in the food supply, so that rabbits can either maximize the use of energy surpluses, or minimize energy deficits. We have shown that $6 \mathrm{MBOA}$ could be involved in such a mechanism. However, we can still predict little about how 6MBOA may act. Subsequent tests have shown that any effects of $6 \mathrm{MBOA}$ are not a simple mimic of melatonin and it is possible that its action in controlling the breeding season may be complex. This may result from $6 \mathrm{MBOA}$ acting at a fundamental level in the hormonal sequence controlling reproduction, and its effect may then be subject to modification. 
The effects of both daylength and nutrition in controlling seasonal physiological cycles of rabbits are clearly interlinked, and may ultimately be controlled by the same fundamental physiological process. This is shown by the combined effect of manipulation of daylength on the voluntary food intake of rabbits and on testicular growth. Seasonal cycles of food intake have been documented previously for herbivores (Pollock, 1975; Simpson et al. 1984; Kay \& Suttie, 1980), and Dark et al. (1983) found that melatonin treatment also had a similar effect to winter daylengths on food intake in montane voles. However, previous studies have shown a depression of food intake under winter daylengths, whereas we have shown it to be stimulated.

Irby et al. (1984) showed that seasonal changes in testicular size in the Australian bush rat were dependent on a combination of environmental conditions. Neither changes in photoperiod nor changes in nutrition were able individually to induce complete testicular regression, and full regression was only observed when they were applied in combination. Our observations suggest a similar situation exists for rabbits, because, while nutrition and photoperiod did alter testicular growth patterns, neither was able to cause highly consistent changes of the magnithde seen in the wild.

Our knowledge of the nutrition of mammalian herbivores is governed mostly by what we know about captive breeds. Our view is of mammals as transducers of energy and nutrients which conform to particular criteria of energetic efficiency according to their design. It is often forgotten how that design arose, and, in attempting its modification by selective breeding or genetical manipulation, it would be easy to lose sight of some of the fundamental features that have made it work. The way in which animals detect environmental changes, interpret these, and respond so as to maximize reproduction or survival, is still poorly understood, and we may benefit from a greater understanding of such processes.

\section{REFERENCES}

Adams, C. E. (1983). Laboratory Animals 17, 340-345.

Berger, P. J., Negus, N. C., Sanders, E. H. \& Gardner, P. D. (1981). Science 214, 69-70.

Boyd, I. L. (1985). Biology of Reproduction 33, 21-29.

Boyd, I. L. (1986a). Journal of Reproduction and Fertility 77, 463-470.

Boyd, I. L. (1986b). Mammal Review 16, 125-130.

Boyd, I. L. (1987). Journal of Reproduction and Fertility 79, 627-633.

Boyd, I. L. \& Myhill, D. G. (1987). Journal of Zoology, London 212, 223-233.

Butterstein, G. M., Schadler, M. H., Lysogorski, E., Robin, L. \& Sipperly, S. (1985). Biology of Reproduction 32, 1018-1023.

Epstein, W. W., Rowsemitt, C. N., Berger, P. J. \& Negus, N. C. (1986). Journal of Chemical Ecology 12, 2011-2019.

Dark, J., Zucker, I. \& Wade, G. N. (1983). American Journal of Physiology 245, R334-R338.

Dawson, A. \& Goldsmith, A. R. (1984). Journal of Endocrinology 100, 213-218.

Irby, D. C., Kerr, J. B., Risbridger, G. P. \& de Kretser, D. M. (1984). Journal of Reproduction and Fertility $70,657-666$.

Kay, R. N. B. \& Suttie, J. M. (1980). Journal of Physiology 310, 34P-35P.

Lincoln, G. A. \& Short, R. V. (1980). Recent Progress in Hormone Research.

Negus, N. C. \& Berger, P. J. (1977). Science 196, 1230-1232.

Nelson, R. J., Dark, J. \& Zucker, I. (1983). Journal of Reproduction and Fertility 69, 473-477.

Partridge, G. G. \& Allan, S. J. (1982). Animal Production 35, 145-155.

Partridge, G. G., Lobley, G. E. \& Fordyce, R. A. (1986). British Journal of Nutrition 56, 199-207.

Pollock, A. M. (1975). Journal of Physiology 244, 95P-96P.

Reiter, R. J. (1980). Endocrine Reviews 1, 109-131.

Reiter, R. J., Johnson, L. Y., Vaughan, M. K. \& Richardson, B. A. (1981). Progress in Clinical and Biological Research 74, 163-178. 
Sadleir, R. M. F. S. (1969). The Ecology of Reproduction in Wild and Domestic Mammals. London: Methuen. Sanders, E. H., Gardner, P. D., Berger, P. J. \& Negus, N. C. (1981). Science 214, 67-69.

Setchell, B. P. (1978). The Mammalian Testis. London: Elek.

Simpson, A. M., Suttie, J. M. \& Kay, R. N. B. (1984). Animal Reproduction Science 6, 291-299.

Turek, F. W., Desjardins, C. \& Menaker, M. (1975). Science 190, $280-282$.

Vaughan, M. K., Richardson, B. A., Petterborg, L. J., Vaughan, G. M. \& Reiter, R. J. (1986). Journal of Reproduction and Fertility 78, 381-387.

Wood, D. H. (1980). Journal of Animal Ecology 49, 55-79.

Yuwiler, A. \& Winters, W. D. (1985). Journal of Pharmacology and Experimental Therapeutics 233, 45-80. 